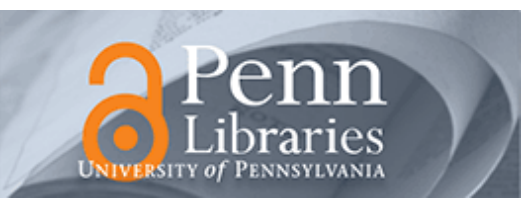

University of Pennsylvania

ScholarlyCommons

4-26-2016

\title{
Associations of Subjective Sleep Quality and Daytime Sleepiness with Cognitive Impairment in Adults and Elders with Heart Failure
}

\author{
Eeeseung Byun \\ Jinyoung Kim \\ University of Pennsylvania \\ Barbara Riegel \\ University of Pennsylvania, briegel@nursing.upenn.edu
}

Follow this and additional works at: https://repository.upenn.edu/nrs

Part of the Cardiology Commons, Cardiovascular Diseases Commons, Circulatory and Respiratory Physiology Commons, Medical Humanities Commons, Neurology Commons, Nursing Commons, and the Sleep Medicine Commons

\section{Recommended Citation}

Byun, E., Kim, J., \& Riegel, B. (2016). Associations of Subjective Sleep Quality and Daytime Sleepiness with Cognitive Impairment in Adults and Elders with Heart Failure. Behavioral Sleep Medicine, 15 (4), 302-317. http://dx.doi.org/10.1080/15402002.2015.1133418

This paper is posted at ScholarlyCommons. https://repository.upenn.edu/nrs/158

For more information, please contact repository@pobox.upenn.edu. 


\title{
Associations of Subjective Sleep Quality and Daytime Sleepiness with Cognitive Impairment in Adults and Elders with Heart Failure
}

\begin{abstract}
This study examined the association of subjective nighttime sleep quality and daytime sleepiness with cognitive impairment in 105 adults ( $<60$ years old) and 167 elders ( $\geq 60$ years old) with heart failure. Nighttime sleep quality and daytime sleepiness were measured by the Pittsburgh Sleep Quality Index and the Epworth Sleepiness Scale. Cognitive impairment was assessed using a neuropsychological battery measuring attention, memory, and processing speed. Multivariate logistic regression was used. In adults, daytime sleepiness was associated with cognitive impairment, whereas poor nighttime sleep quality was associated with cognitive impairment in elders. Age may play an important role in how sleep impacts cognition in persons with heart failure. Improving nighttime sleep quality and daytime sleepiness in this population may improve cognition.

\section{Disciplines}

Cardiology | Cardiovascular Diseases | Circulatory and Respiratory Physiology | Medical Humanities | Medicine and Health Sciences | Neurology | Nursing | Sleep Medicine
\end{abstract}


Title: Associations of Subjective Sleep Quality and Daytime Sleepiness with Cognitive Impairment in Adults and Elders with Heart Failure Short Form of the Title: Sleep Quality, Daytime Sleepiness and Cognition

\author{
Author Information \\ Eeeseung Byun, PhD, RN (Corresponding Author) \\ Postdoctoral Fellow \\ Department of Family Health Care Nursing \\ University of California San Francisco School of Nursing \\ 2 Koret Way, Room N405E, Box 0606 \\ San Francisco, CA 94143 \\ Tel: (267) 968-7012
}

Fax: 415-753-2161

Email: Eeeseung.Byun@ucsf.edu

Jinyoung Kim, PhD, RN

Assistant Professor of Nursing

University of Pennsylvania School of Nursing

418 Curie Blvd.

Philadelphia, PA 19104-4217

Tel: (215)-898-4984

Email: jinki@nursing.upenn.edu 


\section{Barbara Riegel, PhD, RN, FAAN, FAHA}

Professor of Nursing, Edith Clemmer Steinbright Chair of Gerontology

Director, Biobehavioral Research Center

University of Pennsylvania School of Nursing

418 Curie Blvd.

Philadelphia, PA 19104-4217

Tel: (215) 898-9927

Email: briegel@nursing.upenn.edu

\section{Acknowledgements}

The parent study for this work was funded by a grant from the National Institutes of Health/National Heart, Lung \& Blood Institute (R01 HL084394-01A1) and by the Philadelphia Veterans Affairs Medical Center, VISN 4 Mental Illness Research, Education, and Clinical Center. The authors gratefully acknowledge the pre-doctoral funding for Eeeseung Byun provided by the National Institutes of Health/National Institute of Nursing Research (T32 NR009356) and the National Hartford Centers of Geriatric Nursing Excellence Patricia G. Archbold Scholarship program from 2010-2012. We also acknowledge the post-doctoral funding for Eeeseung Byun by the National Institutes of Health/National Institute of Nursing Research (T32 NR007088). The authors also gratefully acknowledge funding for Jinyoung Kim by the National Institutes of Health/National Institute of Nursing Research (R00 NR013177). 


\title{
Associations of Subjective Sleep Quality and Daytime Sleepiness with \\ Cognitive Impairment in Adults and Elders with Heart Failure
}

\begin{abstract}
This study examined the association of subjective nighttime sleep quality and daytime sleepiness with cognitive impairment in 105 adults ( $<60$ years old) and 167 elders ( $\geq 60$ years old) with heart failure. Nighttime sleep quality and daytime sleepiness were measured by the Pittsburgh Sleep Quality Index and the Epworth Sleepiness Scale. Cognitive impairment was assessed using a neuropsychological battery measuring attention, memory and processing speed. Multivariate logistic regression was used. In adults, daytime sleepiness was associated with cognitive impairment, whereas poor nighttime sleep quality was associated with cognitive impairment in elders. Age may play an important role how sleep impacts cognition in persons with heart failure. Improving nighttime sleep quality and daytime sleepiness in this population may improve cognition.
\end{abstract}




\section{Introduction}

Heart failure (HF) is one of the most prevalent chronic conditions in developed and developing countries; in the United States, heart failure affects approximately 5.7 million people (Mozaffarian et al., 2015). Cognitive impairment, such as memory loss, attention deficit and slow processing speed, are common in persons with HF (Gure et al., 2012; Pressler et al., 2010). Approximately $25-50 \%$ of persons with HF test positively with evidence of cognitive impairment (Pressler, 2008; Staniforth, Kinnear, \& Cowley, 2001). Despite a burgeoning literature on the topic, the underlying mechanisms remain unclear. In HF, disease severity, microemboli, and cerebral hypoperfusion are thought to contribute to cognitive impairment (Heckman et al., 2007; Jesus et al., 2006; Staniforth et al., 2001). Older age is also recognized as a contributor (Heckman et al., 2007). Specifically, elders with HF are more likely to have cognitive impairment compared to elders without HF (Qiu et al., 2006; Tilvis et al., 2004), suggesting that both processes of aging and HF contribute to cognitive impairment in this population. In elders with $\mathrm{HF}$, cognitive impairment has been related to the severity of HF symptoms and in particular to left ventricular systolic dysfunction (Heckman et al., 2007).

Sleep disturbances are also common in individuals with HF, with 35-70\% complaining of this problem (Broström, Strömberg, Dahlström, \& Fridlund, 2004; Chen \& Clark, 2007; Erickson, Westlake, Dracup, Woo, \& Hage, 2003). Sleep disturbances in HF are related to symptoms such as fatigue, depression, and daytime sleepiness (Redeker, 2008). Chen et al. (2010) reported that poor nighttime sleep quality is associated with poor health-related quality of life in HF (Chen, Clark, Tsai, \& Lin, 2010). Heart failure patients with daytime sleepiness are more likely to have poor medication adherence than those without daytime sleepiness (Knafl \& Riegel, 2014; Riegel et al., 2011), which can lead to unplanned hospitalization (Riegel \& Knafl, 
2013).

Both HF and cognitive impairment increase the risk of early mortality. Cognitive impairment is known to be related to poor self-care (Bauer et al., 2012; Dickson, Tkacs, \& Riegel, 2007). It may be that mortality is higher when patients are unable to recognize worsening HF symptoms or manage their complex medical regimens. If sleep disturbance is related to cognitive impairment in HF, improving sleep may improve cognitive function, which may improve self-care and symptom management in these patients.

The extent to which characteristics of sleep are associated with cognitive impairment in HF is not well studied. This relationship may differ in adults and elders with HF because of the overlay of age-related changes in cognition and sleep. A meta-analysis revealed that, in a healthy population, there are significant changes in sleep parameters (e.g., total sleep time, percentage of REM sleep) with age from early adulthood to age 60 years, but minimal decline in sleep patterns after age 60 years (Ohayon, Carskadon, Guilleminault, \& Vitiello, 2004). However, others have reported that sleep disturbances and cognitive impairment are related to aging (Blackwell et al., 2014; Heckman et al., 2007; Institute of Medicine, 2015). Elders with an acute (e.g. stroke) or chronic illness diagnosis (e.g. arthritis) often report sleep-related problems such as breathing pauses, snoring, daytime sleepiness, restless legs, or poor sleep quality (Newman, Enright, Manolio, Haponik, \& Wahl, 1997). Thus, the purpose of the study was to examine the association of subjective nighttime sleep quality and daytime sleepiness with cognitive impairment in adults and elders with HF. We hypothesized that subjective nighttime sleep quality and daytime sleepiness would be worse in HF patients with cognitive impairment compared to HF patients without cognitive impairment and explored whether the associations would differ when age was taken into account. 


\section{Methods}

This cross-sectional study was a secondary analysis of baseline data from a prospective longitudinal cohort study of adults with HF (Riegel et al., 2011). The purpose of the parent study was to test the hypothesis that adults with HF and excessive daytime sleepiness would, over time, experience more problems with self-care than those without excessive daytime sleepiness. The major finding of the parent study was that adults with HF and excessive daytime sleepiness demonstrated significantly higher medication nonadherence compared to those without excessive daytime sleepiness, regardless of cognitive status (Riegel et al., 2011). Patients were recruited from three outpatient settings in Philadelphia, Pennsylvania and Newark, Delaware. The study was approved by the Institutional Review Board from all recruitment sites and all participants provided written informed consent. To be included in the parent study, patients had to (a) have symptomatic HF confirmed by echocardiographic and clinical evidence, (b) be able to speak and read English for reliable cognition testing, and (c) have a score $\geq 24$ on the Telephone Screen of Impaired Cognition scale, which indicates that the person is either cognitively intact or has mild cognitive impairment (Brandt \& Folstein, 2003). Those with severe cognitive impairment such as dementia were excluded. Patients with major depression were excluded because of the known influence of depression on cognition (Van der Mussele et al., 2014). Patients described in the medical record as having major depression were not approached. Patients were screened with the Patient Health Questionnaire (Kroenke \& Spitzer, 2002); those who reported $\geq 5$ of the 9 symptoms more than half the days in the past 2 weeks were excluded if one of the symptoms was depressed mood or anhedonia. Patients who lived in a long-term-care setting, worked night shift or rotating shifts, planned to move out of the area, or had renal failure requiring dialysis, a history of drug or alcohol abuse in the preceding year, or whose death was imminent were 
excluded based on the goals of the parent study.

For the parent study, 333 patients with HF were eligible for inclusion and 280 were enrolled and followed for 6 months. Cognitive testing data were missing on 8 of these participants, so the present analysis included a total of 272 individuals. We divided participants into two age cohorts: 105 adults ( $<60$ years), 167 elders $(\geq 60$ years).

\section{Measurement}

\section{Nighttime Sleep Quality}

The 19-item Pittsburgh Sleep Quality Index was used to measure nighttime sleep quality and types of sleep disturbances over the past month (Buysse, Reynolds, Monk, Berman, \& Kupfer, 1989). This scale includes seven component scores: subjective sleep quality, sleep latency, sleep duration, habitual sleep efficiency, sleep disturbances, use of sleeping medication, and daytime dysfunction. Scores range from 0 to 21 , with higher scores indicating poorer sleep quality. A global Pittsburgh Sleep Quality Index score $>5$ is a sensitive and specific measure of poor sleep quality (Buysse et al., 1989). This scale has demonstrated good reliability and validity across many patient populations (Buysse et al., 1989).

\section{Daytime Sleepiness}

The 8-item Epworth Sleepiness Scale was used to assess the likelihood of falling asleep in common daily situations (Johns, 1992). Each item on a 4 point scale is summed with scores ranging 0 to 24 , with higher scores indicating greater sleepiness. A cutoff point of $>10$ is considered sleepy (Johns, 1992). The scale has well established validity and reliability (Johns, 1992).

\section{Sleep Disordered Breathing}

At enrollment, the medical record was reviewed and a physician diagnosis of sleep 
disordered breathing based on polysomnography was obtained. If documentation of recent sleep testing was not found in the medical record, sleep was assessed in the home using an unattended sleep study device, the Embletta (Medcare, Buffalo, New York, USA). Individuals with an apnea hypopnea index $(\mathrm{AHI}) \geq 5$ were classified as having sleep disordered breathing (Ruehland et al., 2009).

\section{Cognitive Impairment}

Neuropsychological tests were administrated to assess the cognitive domains known to be influenced by sleep deprivation (Lim \& Dinges, 2010). The test battery included the Psychomotor Vigilance Test (Basner \& Dinges, 2011; Dinges et al., 1997; simple attention), the Trail Making Test B (Reitan, 1992; complex attention), the Digital Symbol-Substitution Test (The Psychological Corporation, 2002; processing speed), the Probed Memory Recall Test (Dinges, Kribbs, Bates, \& Carlin, 1993; working memory), and the Letter Number Sequencing Test (The Psychological Corporation, 2002; short-term memory). Each measure in the Neuropsychological Battery is described in Table 1.

The number of tests on which subjects scored below their norm was used as the measure of cognitive status. Specifically, participants scoring 1.5 standard deviations below the norm (Jak et al., 2009) on two or more of the five neuropsychological tests, the Psychomotor Vigilance Test, Trail Making Test B, Digital Symbol-Substitution Test, Probed Memory Recall Test, and Letter Number Sequencing Test, were classified as having cognitive impairment.

\section{Demographic and Clinical Characteristics}

Demographic characteristics such as age, gender, race, education, and income were collected. Education was categorized into one of three groups: less than high school, high school, or any college. In addition, the American National Adult Reading Test (ANART) was used to 
assess premorbid intellect (Gladsjo, Heaton, Palmer, Taylor, \& Jeste, 1999). Participants were asked to read a list of 50 phonetically irregular words aloud. The number of words pronounced correctly was used in the analysis as a covariate. Participants were asked to rate their household income as: 1) comfortable, have more than enough to make ends meet; 2) having enough to make ends meet; or 3) not having enough to make ends meet. They were interviewed about the number of hours they typically slept at night. Clinical information such as months with HF, type of HF or HF etiology and left ventricular ejection fraction was collected from the medical record. A cardiologist scored the New York Heart Association (NYHA) functional class (class I is without symptoms, class II is symptoms with exertion, class III is symptoms with any physical activity, and class IV is symptoms at rest), which was used as a measure of HF severity (Raphael et al., 2007). Comorbidity was assessed using the Charlson Index, with higher scores indicating more comorbid illnesses (Charlson, Pompei, Ales, \& MacKenzie, 1987). Although those with major depression were excluded, as described above, depressive symptoms were assessed at each testing interval using the Patient Health Questionnaire-9 (Kroenke \& Spitzer, 2002). Total scores range from 0 to 24 , with severity classified as none (score 1 to 4 ), mild (5 to 9), moderate (10 to 14), moderately severe (15 to 19 ) and severe (20 to 27 ) depression (Kroenke \& Spitzer, 2002).

\section{Statistical Analysis}

Measures of central tendency were used to describe demographic and clinical characteristics. Differences between adults and elders were tested with independent sample ttests or Chi-square test of independence. Independent sample t-tests or Chi-square test of independence were also used to compare sleep characteristics of participants with and without cognitive impairment.

Pearson correlation was used to explore relationships between subjective nighttime sleep 
quality, subjective daytime sleepiness and each cognitive test. Multivariate logistic regression was used to test the impact of nighttime sleep quality and daytime sleepiness on cognitive impairment. The Probed Memory Recall Test is influenced by age and gender (Kim, Dinges, \& Young, 2007), so age and gender were adjusted in the analysis as were race, years of education, premorbid intellect, severity of HF, comorbidity, depression and recruitment site. The model was tested twice: adults ( $<60$ years of age) and elders ( $\geq 60$ years of age). In addition, we controlled for age as a continuous variable in each of these analyses. For all analyses, $p<.05$ in a two-sided test was considered statistically significant. All analyses were performed using SPSS version 22 software for Windows (IBM Corporation, Armonk, NY).

\section{Results}

Demographic and clinical characteristics for the sample of 272 individuals (105 adults $[<60$ years of age] and 167 elders $[\geq 60$ years of age $]$ ) are shown in Table 2. Most were White males who were functionally compromised. The mean ages for the adults and elders were $50.0( \pm$ 7.7 , range $24-59$, median 51) and 69.8 ( \pm 7.4 , range $60-89$, median 68$)$, respectively. Sleep characteristics and statistical differences ( $p$ values) between participants with and without cognitive impairment are shown in Table 3. Total sleep times were below 8 hours per night. Most of the sample had poor sleep quality but daytime sleepiness was not high in most. More than half of the sample had sleep disordered breathing. In those with an apnea hypopnea index available (only $25 \%$ in adults and $23 \%$ in elders), $38 \%$ of adults and $63 \%$ of elders had an AHI $\geq$ 5. A summary of the cognitive measures is shown in Table 4. The prevalence of cognitive impairment was $32 \%$ in adults and $44 \%$ in elders.

The relationships between scores on the Pittsburgh Sleep Quality Index, the Epworth Sleepiness Scale, and each cognition test are shown in Table 5. Poorer subjective nighttime sleep 
quality was positively associated with more daytime sleepiness $(r=0.384, p<.001$ in adults; $r=$ $0.160, p=.038$ in elders). In adults, with the exception of the digit symbol-substitution test, more daytime sleepiness was significantly associated with poorer performance in each cognitive test. In elders, poorer nighttime sleep quality was significantly associated with worse performance on each cognitive test.

In adults, each additional one unit increase in daytime sleepiness increased the odds of cognitive impairment by 25\% (Odds Ratio [OR] 1.25, 95\% Confidence Interval [CI] 1.08-1.45, $p=.003$, see Table 6). Each additional one unit increase in premorbid intellect decreased the odds of cognitive impairment by $11 \%$ (OR .89, 95\% CI .83-.96, $\mathrm{p}=.001)$. In elders, each additional one unit increase in poor nighttime sleep quality increased the odds of cognitive impairment by $16 \%$ (OR 1.16, 95\% CI 1.03-1.31, $p=.017)$. For each additional year in age, the odds of cognitive impairment increased by $8 \%(\mathrm{OR}=1.08,95 \%$ CI $1.01-1.14, p=.015)$. There was a statistical difference in cognitive impairment between sites.

\section{Discussion}

The major finding from our study was that in both age groups, the prevalence of cognitive impairment was high, and sleep variables were associated with cognition. The majority of participants had poor sleep quality and approximately one third in each age group had excessive daytime sleepiness. Specifically, in elders with HF, poor subjective nighttime sleep quality was significantly associated with cognitive impairment after adjusting for covariates. In adults younger than 60 years, subjective excessive daytime sleepiness was associated with worse cognitive performance. Another factor influencing cognitive impairment in the adults was premorbid intellect. In the elders, older age was positively associated with cognitive impairment.

Our findings are similar to those of Garcia et al. (2012) who reported a significant 
association of poorer sleep quality with reduced performance on tests of attention/executive function, with a trend for memory but not language in elders with HF. Their sample included individuals between 50 and 85 years of age and they controlled for age in the analyses. Our results are more nuanced because we divided our sample into two separate age groups for analysis and revealed different sleep characteristics in each group associated with cognitive impairment: daytime sleepiness in the adults and nighttime sleep quality in the elders. We also assessed cognitive status using a rigorous neuropsychological battery of tests measuring the major cognitive domains influenced by sleep loss and we confirmed that night time sleep quality was associated with cognitive impairment in elders. Using this neuropsychological battery allowed us to identify subtle relationships between sleep and cognition that others have not previously identified: associations of more daytime sleepiness with poorer performance in the majority of the cognitive tests in the adults and associations of poorer nighttime sleep quality with worse performance on each cognitive test in the elders.

One possible mechanism of cognitive impairment in $\mathrm{HF}$ is cerebral hypoperfusion (Heckman et al., 2007; Staniforth et al., 2001). Heart failure causes hypoperfusion due to an inability of the heart to pump adequately to perfuse the brain. In addition, impaired sleep has been related to decreased cerebral flow in the right and left frontal lobes (Miyata et al., 2010). If impaired sleep aggravates cerebral hypoperfusion in HF, it could contribute to other factors causing cognitive impairment (Garcia et al., 2012). Another plausible mechanism is that sleep disturbances impair memory consolidation and restoration of brain function during the night (Jelicic et al., 2002; Sterniczuk, Theou, Rusak, \& Rockwood, 2013). Experimental models of total or partial sleep deprivation suggest that poor sleep might contribute to cognitive impairment by promoting neuroinflammation or changing neuronal morphology in the prefrontal or 
hippocampus areas that regulate learning and memory processes (Acosta-peña et al., 2015; Zhu et al., 2012). Susceptibility of the specific brain area to sleep deprivation has been seen by regional brain-activation studies using positron-emission tomography (PET) and functional magnetic resonance imaging (fMRI) (Thomas et al., 2000; Wu et al., 1991). Metabolic fluctuations in the prefrontal cortex and phasic electroencephalography (EEG) changes associated with alertness and attention in sleep deprivation might be related to cognitive impairment.

The majority of previous experimental studies examined the effect of acute sleep deprivation. However, recent studies suggest that chronic partial sleep deprivation (3 days to 2 weeks) decreases attention, memory, and cognitive speed or accuracy (Drake et al., 2001; Van Dongen, Maislin, Mullington, \& Dinges, 2003). Information regarding neurocognitive consequences of self-reported sleep quality is still lacking. Further research in a larger cohort of HF with longitudinal follow up is required to clarify mechanisms of the relationship between nighttime sleep quality, excessive daytime sleepiness, and cognitive impairment.

In patients with HF, sleep problems are common and closely related to symptoms and prognosis. In HF patients, sleep problems have been associated with fatigue, weakness, and irregular heartbeats, mediated by hyperarousal, sympathetic activation, impaired immune-system functioning, and stimulation of the hypothalamic pituitary adrenal axis (Redeker, 2008). Redeker and Stein (2006) reported that patients diagnosed with systolic HF complained more of prolonged sleep latency, frequent sleep wakening during the night, and early morning awakening, compared with a non-HF control group. Some researchers reported between $21 \%$ and $44 \%$ of HF patients had excessive daytime sleepiness, which was higher than that of those without HF (Broström et al., 2004; Redeker \& Stein, 2006). Others reported that patients with both HF and 
obstructive sleep apnea had less subjective daytime sleepiness compared with a community dwelling sample (Somers et al., 2008). Despite the lack of subjective perception of excessive daytime sleepiness, in individuals with HF and sleep-disordered breathing there was evidence of objective sleepiness (Arzt et al., 2006; Rao et al., 2006). Lack of sleepiness in HF may be due to autonomic stimulation (Aggarwal et al., 2002; Arzt et al., 2006; MacDonald, Fang, Pittman, White, \& Malhotra, 2008; Rao et al., 2006), but further research is warranted to understand why individuals with HF do not complain of daytime sleepiness.

It is not clear why excessive daytime sleepiness was associated with cognitive impairment only in the adults in our study, whereas nighttime sleep quality was associated with cognitive impairment in the elders with HF. These results are consistent with a prior study in which an association was found between excessive daytime sleepiness and napping in adults, but no association of excessive daytime sleepiness with napping in elders (Ohayon \& Vecchierini, 2002). It may be that adults are more sensitive to somatic input and sleep drive than elders (Khalsa, Rudrauf, \& Tranel, 2009). It is also possible that adults are more likely to be working and experiencing sleepiness during normal activities, but feel that they cannot nap due to work responsibilities (Ohayon \& Vecchierini, 2002).

In elders, nighttime sleep quality was associated with cognitive impairment, as others have noted in elders with HF (Garcia et al., 2012) and in a community sample of elders (Blackwell et al., 2014; Nebes, Buysse, Halligan, Houck, \& Monk, 2009). Some investigators have reported that, in community-dwelling elders, daytime sleepiness was associated with cognitive impairment (Foley et al., 2001; Ohayon \& Vecchierini, 2002), but another study reported no association with cognitive impairment (Blackwell et al., 2014). Further research is needed to clarify the relationships between age, sleep, and cognition. 
Major limitations of this study are the cross-sectional analysis and the lack of objective sleep measures. In our secondary analysis, AHI was available only in one quarter of the subjects and it was not associated with cognitive impairment. Further research with objective sleep measures such as actigraphy or polysomnography are required to gain a better understanding of sleep disturbances in this population. Another limitation is the exclusion of severely cognitively impaired patients. It is plausible that people with severe cognitive impairment have more sleep disturbances and more daytime sleepiness than our sample. We also did not include a control group without HF, which would have expanded our understanding of these results. Individuals with HF may have increased risk of sleep disturbances and cognitive impairment than those without HF. Associations between sleep and cognition may also have been stronger in the HF group than those in a control group. Strengths of this study include the separate analysis of adults and elders, given that aging is closely related to cognitive function, use of a rigorous neuropsychological battery, and a large proportion of minority group participants.

In summary, we found that more daytime sleepiness was associated with cognitive impairment in adults with HF. In addition, poor nighttime sleep quality was associated with cognitive impairment in elders with HF. Improving nighttime sleep quality and daytime sleepiness may improve cognition in this population. 


\section{References}

Acosta-peña, E., Camacho-Abrego, I., Melgarejo-Gutiérrez, M., Flores, G., Drucker-Colín, R., \& García-García, F. (2015). Sleep deprivation induces differential morphological changes in the hippocampus and prefrontal cortex in young and old rats. Synapse, 69(1), 15-25.

Aggarwal, A., Esler, M. D., Lambert, G. W., Hastings, J., Johnston, L., \& Kaye, D. M. (2002). Norepinephrine turnover is increased in suprabulbar subcortical brain regions and is related to whole-body sympathetic activity in human heart failure. Circulation, 105(9), 1031-1033.

Arzt, M., Young, T., Finn, L., Skatrud, J. B., Ryan, C. M., Newton, G. E., et al. (2006). Sleepiness and sleep in patients with both systolic heart failure and obstructive sleep apnea. Arch Intern Med, 166(16), 1716-1722.

Basner, M., \& Dinges, D. F. (2011). Maximizing Sensitivity of the Psychomotor Vigilance Test (PVT) to Sleep Loss. Sleep, 34(5), 581-591.

Bauer, L., Pozehl, B., Hertzog, M., Johnson, J., Zimmerman, L., \& Filipi, M. (2012). A brief neuropsychological battery for use in the chronic heart failure population. European Journal of Cardiovascular Nursing, 11(2), 223-230.

Blackwell, T., Yaffe, K., Laffan, A., Ancoli-Israel, S., Redline, S., Ensrud, K. E., et al. (2014). Associations of Objectively and Subjectively Measured Sleep Quality with Subsequent Cognitive Decline in Older Community-Dwelling Men: The MrOS Sleep Study. Sleep, $37(4), 655-663$.

Brandt, J., \& Folstein, M. F. (2003). Telephone interview for cognitive status. Lutz, FL: Psychological Assessment Resources. 
Broström, A., Strömberg, A., Dahlström, U., \& Fridlund, B. (2004). Sleep Difficulties, Daytime Sleepiness, and Health-related Quality of Life in Patients With Chronic Heart Failure. Journal of Cardiovascular Nursing, 19(4), 234-242.

Buysse, D. J., Reynolds, C. F., Monk, T. H., Berman, S. R., \& Kupfer, D. J. (1989). The Pittsburgh Sleep Quality Index: a new instrument for psychiatric practice and research. Psychiatry Research, 28(2), 193-213.

Charlson, M. E., Pompei, P., Ales, K. L., \& MacKenzie, C. R. (1987). A new method of classifying prognostic comorbidity in longitudinal studies: development and validation. $J$ Chronic Dis, 40(5), 373-383.

Chen, H. M., \& Clark, A. P. (2007). Sleep Disturbances in People Living With Heart Failure. Journal of Cardiovascular Nursing, 22(3), 177-185 110.1097/1001.JCN.0000267823.0000219826.ca.

Chen, H. M., Clark, A. P., Tsai, L. M., \& Lin, C. C. (2010). Self-Reported Health-Related Quality of Life and Sleep Disturbances in Taiwanese People With Heart Failure. Journal of Cardiovascular Nursing, 25(6), 503-513.

Dickson, V. V., Tkacs, N., \& Riegel, B. (2007). Cognitive influences on self-care decision making in persons with heart failure. American Heart Journal, 154(3), 424-431.

Dinges, D., Kribbs, N., Bates, B., \& Carlin, M. (1993). A very brief probed recall memory task: Sensitivity to sleep loss. Sleep Research, 22, 330.

Dinges, D. F., Pack, F., Williams, K., Gillen, K. A., Powell, J. W., Ott, G. E., et al. (1997). Cumulative sleepiness, mood disturbance, and psychomotor vigilance performance decrements during a week of sleep restricted to 4-5 hours per night. Sleep, 20(4), 267277. 
Drake, C. L., Roehrs, T. A., Burduvali, E., Bonahoom, A., Rosekind, M., \& Roth, T. (2001). Effects of rapid versus slow accumulation of eight hours of sleep loss. Psychophysiology, $38(6), 979-987$.

Erickson, V. S., Westlake, C. A., Dracup, K. A., Woo, M. A., \& Hage, A. (2003). Sleep Disturbance Symptoms in Patients With Heart Failure. AACN Advanced Critical Care, 14(4), 477-487.

Foley, D., Monjan, A., Masaki, K., Ross, W., Havlik, R., White, L., et al. (2001). Daytime Sleepiness Is Associated with 3-Year Incident Dementia and Cognitive Decline in Older Japanese-American Men. Journal of the American Geriatrics Society, 49(12), 1628-1632.

Garcia, S., Alosco, M. L., Spitznagel, M. B., Cohen, R., Raz, N., Sweet, L., et al. (2012). Poor sleep quality and reduced cognitive function in persons with heart failure. International Journal of Cardiology, 156(2), 248-249.

Gladsjo, J. A., Heaton, R. K., Palmer, B. W., Taylor, M. J., \& Jeste, D. V. (1999). Use of oral reading to estimate premorbid intellectual and neuropsychological functioning. Journal of the International Neuropsychological Society, 5(3), 247-254.

Gure, T. R., Blaum, C. S., Giordani, B., Koelling, T. M., Galecki, A., Pressler, S. J., et al. (2012). Prevalence of cognitive impairment in older adults with heart failure. J Am Geriatr Soc, 60(9), 1724-1729.

Heckman, G. A., Patterson, C. J., Demers, C., Onge, J. S., Turpie, I. D., \& McKelvie, R. S. (2007). Heart failure and cognitive impairment: Challenges and opportunities. [Review]. Clinical Interventions in Aging, 2(2), 209-218.

Institute of Medicine (2015) Cognitive aging: Progress in understanding and opportunities for action. Washington, DC: The National Academies Press. 
Jak, A. J., Bondi, M. W., Delano-Wood, L., Wierenga, C., Corey-Bloom, J., Salmon, D. P., et al. (2009). Quantification of five neuropsychological approaches to defining mild cognitive impairment. Am J Geriatr Psychiatry, 17(5), 368-375.

Jelicic, M., Bosma, H., Ponds, R. W., Van Boxtel, M. P., Houx, P. J., \& Jolles, J. (2002).

Subjective sleep problems in later life as predictors of cognitive decline. Report from the Maastricht Ageing Study (MAAS). Int J Geriatr Psychiatry, 17(1), 73-77.

Jesus, P. A., Vieira-de-Melo, R. M., Reis, F. J., Viana, L. C., Lacerda, A., Dias, J. S., et al. (2006). Cognitive dysfunction in congestive heart failure: transcranial Doppler evidence of microembolic etiology. Arq Neuropsiquiatr, 64(2A), 207-210.

Johns, M. W. (1992). Reliability and factor analysis of the Epworth Sleepiness Scale. Sleep, 15(4), 376-381.

Khalsa, S. S., Rudrauf, D., \& Tranel, D. (2009). Interoceptive awareness declines with age. Psychophysiology, 46(6), 1130-1136.

Kim, H., Dinges, D. F., \& Young, T. (2007). Sleep-disordered breathing and psychomotor vigilance in a community-based sample. Sleep, 30(10), 1309-1316.

Knafl, G. J., \& Riegel, B. (2014). What puts heart failure patients at risk for poor medication adherence? Patient Prefer Adherence, 8, 1007-1018.

Kroenke, K., \& Spitzer, R. L. (2002). The PHQ-9: A new depression diagnostic and severity measure. Psychiatric Annals, 32(9), 509-515.

Lim, J., \& Dinges, D. F. (2010). A Meta-Analysis of the Impact of Short-Term Sleep Deprivation on Cognitive Variables. Psychological Bulletin, 136(3), 375-389. 
MacDonald, M., Fang, J., Pittman, S. D., White, D. P., \& Malhotra, A. (2008). The current prevalence of sleep disordered breathing in congestive heart failure patients treated with beta-blockers. J Clin Sleep Med, 4(1), 38-42.

Miyata, S., Noda, A., Ozaki, N., Hara, Y., Minoshima, M., Iwamoto, K., et al. (2010). Insufficient sleep impairs driving performance and cognitive function. Neuroscience Letters, 469(2), 229-233.

Mozaffarian, D., Benjamin, E. J., Go, A. S., Arnett, D. K., Blaha, M. J., Cushman, M., . . . Turner, M. B. (2015). Heart Disease and Stroke Statistics—2015 Update: A Report From the American Heart Association. Circulation, 131(4), e29-e322. doi: 10.1161/cir.0000000000000152

Nebes, R. D., Buysse, D. J., Halligan, E. M., Houck, P. R., \& Monk, T. H. (2009). Self-Reported Sleep Quality Predicts Poor Cognitive Performance in Healthy Older Adults. The Journals of Gerontology Series B: Psychological Sciences and Social Sciences, 64B(2), 180-187.

Newman, A. B., Enright, P. L., Manolio, T. A., Haponik, E. F., \& Wahl, P. W. (1997). Sleep disturbance, psychosocial correlates, and cardiovascular disease in 5201 older adults: The cardiovascular health study. Journal of the American Geriatrics Society, 45(1), 1-7.

Ohayon, M. M., \& Vecchierini, M. (2002). DAytime sleepiness and cognitive impairment in the elderly population. Archives of Internal Medicine, 162(2), 201-208.

Pressler, S. J. (2008). Cognitive Functioning and Chronic Heart Failure: A Review of the Literature (2002-July 2007). Journal of Cardiovascular Nursing, 23(3), 239-249 210.1097/1001.JCN.0000305096.0000309710.ec. 
Pressler, S. J., Subramanian, U., Kareken, D., Perkins, S. M., Gradus-Pizlo, I., Sauve, M. J., et al. (2010). Cognitive deficits in chronic heart failure. Nurs Res, 59(2), 127-139.

The Psychological Corporation. WAIS-III technical manual. (2002). San Antonio, TX: Harcourt Assessment Co.

Ohayon, M. M., Carskadon, M. A., Guilleminault, C., \& Vitiello, M. V. (2004). Meta-analysis of quantitative sleep parameters from childhood to old age in healthy individuals: developing normative sleep values across the human lifespan. Sleep, 27(7), 1255-1273.

Qiu, C., Winblad, B., Marengoni, A., Klarin, I., Fastbom, J., \& Fratiglioni, L. (2006). Heart failure and risk of dementia and Alzheimer disease: a population-based cohort study. Arch Intern Med, 166(9), 1003-1008.

Rao, A., Georgiadou, P., Francis, D. P., Johnson, A., Kremastinos, D. T., Simonds, A. K., et al. (2006). Sleep-disordered breathing in a general heart failure population: relationships to neurohumoral activation and subjective symptoms. J Sleep Res, 15(1), 81-88.

Raphael, C., Briscoe, C., Davies, J., Ian Whinnett, Z., Manisty, C., Sutton, R., et al. (2007). Limitations of the New York Heart Association functional classification system and selfreported walking distances in chronic heart failure. Heart, 93(4), 476-482.

Redeker, N. S. (2008). Sleep disturbance in people with heart failure - Implications for self-care. Journal of Cardiovascular Nursing, 23(3), 231-238.

Redeker, N. S., \& Stein, S. (2006). Characteristics of sleep in patients with stable heart failure versus a comparison group. Heart \& Lung: The Journal of Acute and Critical Care, $35(4), 252-261$.

Reitan, R. (1992). Trail making test. Tucson, AZ: Reitan Neuropsychological Laboratory. 
Riegel, B., \& Knafl, G. J. (2013). Electronically monitored medication adherence predicts hospitalization in heart failure patients. Patient Prefer Adherence, 8, 1-13.

Riegel, B., Moelter, S. T., Ratcliffe, S. J., Pressler, S. J., De Geest, S., Potashnik, S., et al. (2011). Excessive Daytime Sleepiness is Associated With Poor Medication Adherence in Adults With Heart Failure. Journal of Cardiac Failure, 17(4), 340-348.

Ruehland, W. R., Rochford, P. D., O'Donoghue, F. J., Pierce, R. J., Singh, P., \& Thornton, A. T. (2009). The new AASM criteria for scoring hypopneas: impact on the apnea hypopnea index. Sleep, 32(2), 150-157.

Somers, V. K., White, D. P., Amin, R., Abraham, W. T., Costa, F., Culebras, A., et al. (2008). Sleep Apnea and Cardiovascular Disease: An American Heart Association/American College of Cardiology Foundation Scientific Statement From the American Heart Association Council for High Blood Pressure Research Professional Education Committee, Council on Clinical Cardiology, Stroke Council, and Council on Cardiovascular Nursing In Collaboration With the National Heart, Lung, and Blood Institute National Center on Sleep Disorders Research (National Institutes of Health). Circulation, 118(10), 1080-1111.

Staniforth, A. D., Kinnear, W. J. M., \& Cowley, A. J. (2001). Cognitive impairment in heart failure with Cheyne-Stokes respiration. Heart, 85(1), 18-22.

Sterniczuk, R., Theou, O., Rusak, B., \& Rockwood, K. (2013). Sleep disturbance is associated with incident dementia and mortality. Curr Alzheimer Res, 10(7), 767-775.

Thomas, M., Sing, H., Belenky, G., Holcomb, H., Mayberg, H., Dannals, R., et al. (2000). Neural basis of alertness and cognitive performance impairments during sleepiness. I. 
Effects of $24 \mathrm{~h}$ of sleep deprivation on waking human regional brain activity. Journal of Sleep Research, 9(4), 335-352.

Tilvis, R. S., Kahonen-Vare, M. H., Jolkkonen, J., Valvanne, J., Pitkala, K. H., \& Strandberg, T. E. (2004). Predictors of cognitive decline and mortality of aged people over a 10-year period. J Gerontol A Biol Sci Med Sci, 59(3), 268-274.

Van der Mussele, S., Fransen, E., Struyfs, H., Luyckx, J., Marien, P., Saerens, J., et al. (2014). Depression in Mild Cognitive Impairment is associated with Progression to Alzheimer's Disease: A Longitudinal Study. J Alzheimers Dis, 42(4), 1239-1250.

Van Dongen, H. P. A., Maislin, G., Mullington, J. M., \& Dinges, D. F. (2003). The cumulative cost of additional wakefulness: Dose-response effects on neurobehavioral functions and sleep physiology from chronic sleep restriction and total sleep deprivation. Sleep, 26(2), $117-126$.

Verhaegen, P., Borchelt, M., \& Smith, J. (2003). Relation between cardiovascular and metabolic disease and cognition in very old age: cross-sectional and longitudinal findings from the berlin aging study. Health Psychol, 22(6), 559-569.

Wu, J. C., Gillin, J. C., Buchsbaum, M. S., Hershey, T., Hazlett, E., Sicotte, N., et al. (1991). The effect of sleep deprivation on cerebral glucose metabolic rate in normal humans assessed with positron emission tomography. Sleep, 14(2), 155-162.

Zhu, B., Dong, Y., Xu, Z., Gompf, H. S., Ward, S. A., Xue, Z., et al. (2012). Sleep disturbance induces neuroinflammation and impairment of learning and memory. Neurobiol Dis, 48(3), 348-355. 
Table 1

Description of Each Measure in the Neuropsychological Battery

\begin{tabular}{|c|c|c|}
\hline Cognitive Domain & $\begin{array}{l}\text { Neuropsychologic } \\
\text { Test }\end{array}$ & Brief Description of the Task \\
\hline Simple Attention & $\begin{array}{l}\text { Psychomotor } \\
\text { Vigilance Task }\end{array}$ & $\begin{array}{l}\text { The Psychomotor Vigilance Test (Basner \& Dinges, } 2011 \text {; Dinges et } \\
\text { al., 1997) was used to assess simple attention. Participants were asked } \\
\text { to respond as rapidly as possible to a series of red digits " } 000 \text { " of light } \\
\text { over a } 10 \text {-minute period. Lapses, the number of times the participant } \\
\text { failed to respond to the signal or failed to respond in a timely manner, } \\
\text { were considered as problems with attention and psychomotor speed. } \\
\text { Transformed lapses } \geq 4.69 \text { were classified as abnormally high and an } \\
\text { indicator of poor attention. }\end{array}$ \\
\hline $\begin{array}{l}\text { Complex } \\
\text { Attention }\end{array}$ & Trail-Making Test B & $\begin{array}{l}\text { The Trail-Making Test B (Reitan, 1992) was used to assess complex } \\
\text { attention. Participants were asked to draw lines to connect circles that } \\
\text { included both numbers and letters in serial order by alternating } \\
\text { between the numbers and letters. The number of seconds required to } \\
\text { complete the task, with higher scores indicating greater impairment, } \\
\text { was used in the analysis. Age-specific norms were used to determine } \\
\text { participants with or without impairment (Reitan, 1992). }\end{array}$ \\
\hline Processing Speed & $\begin{array}{l}\text { Digit Symbol- } \\
\text { Substitution Test }\end{array}$ & $\begin{array}{l}\text { The Digit Symbol-Substitution Test (The Psychological Corporation, } \\
\text { 2002) was used to assess processing speed. Participants were provided } \\
\text { a pair of each unique number and different nonsense symbol. They } \\
\text { were asked to transcribe the corresponding symbol for each paired } \\
\text { number. The number correctly transcribed in } 120 \text { seconds was } \\
\text { assessed. Age-specific norms were used to determine participants with } \\
\text { and without impairment (The Psychological Corporation, 2002). }\end{array}$ \\
\hline Working Memory & $\begin{array}{l}\text { Probed-Memory } \\
\text { Recall Task }\end{array}$ & $\begin{array}{l}\text { The Probed Memory Recall (Dinges et al., 1993) was used to assess } \\
\text { working memory. Participants were shown a list of } 4 \text { word pairs for } 30 \\
\text { seconds. Then they were tested on other topics for } 10 \text { minutes. Next, } \\
\text { participants were provided a list of } 1 \text { word in each pair with different } \\
\text { order and asked to recall all } 4 \text { of the paired words within } 1 \text { minute. } \\
\text { Participants recalling } \leq 1 \text { word were considered impaired (Dinges et } \\
\text { al., 1993). }\end{array}$ \\
\hline $\begin{array}{l}\text { Short-term } \\
\text { memory }\end{array}$ & $\begin{array}{l}\text { Letter Number } \\
\text { Sequencing Subtest }\end{array}$ & $\begin{array}{l}\text { The Letter Number Sequencing subtest (The Psychological } \\
\text { Corporation, 2002) was used to assess short-term memory. Participants } \\
\text { were asked to read a sequence of numbers and letters in a specified } \\
\text { random order. Then, they were asked to recall the numbers in } \\
\text { ascending order and the letters in alphabetical order. The number of } \\
\text { correctly recalled sequences was counted and age-adjusted scores were } \\
\text { used (The Psychological Corporation, 2002). }\end{array}$ \\
\hline
\end{tabular}


Table 2

Demographic and Clinical Characteristics

\begin{tabular}{|c|c|c|c|}
\hline Characteristics & $\begin{array}{c}\text { Adults }(N=105) \\
\text { Mean }(\mathrm{SD}) \\
\text { or } N(\%)\end{array}$ & $\begin{array}{c}\text { Elders }(N=167) \\
\text { Mean }(\mathrm{SD}) \\
\text { or } N(\%)\end{array}$ & $p$ value \\
\hline \multicolumn{4}{|l|}{ Demographic Characteristics } \\
\hline Age & $50.0 \pm 7.74$ & $69.8 \pm 7.42$ & $<.001$ \\
\hline Gender & & & .049 \\
\hline Male & $60(57 \%)$ & $115(69 \%)$ & \\
\hline Female & $45(43 \%)$ & $52(31 \%)$ & \\
\hline Race & & & .056 \\
\hline White & $59(56 \%)$ & $113(68 \%)$ & \\
\hline Black/Others & $46(44 \%)$ & $54(32 \%)$ & \\
\hline Education in Years & $14.13 \pm 2.68$ & $13.76 \pm 3.01$ & .300 \\
\hline Education & & & .215 \\
\hline Less than high school & $6(6 \%)$ & $20(12 \%)$ & \\
\hline High school & $38(36 \%)$ & $60(36 \%)$ & \\
\hline More than college & $61(58 \%)$ & $87(52 \%)$ & \\
\hline American National Adult Reading Test & $29.38 \pm 12.68$ & $\begin{array}{c}30.52 \pm 11.17 \\
\quad(N=166)\end{array}$ & .439 \\
\hline Income & & & .112 \\
\hline Have more than enough & $29(28 \%)$ & $66(40 \%)$ & \\
\hline Have enough & $55(52 \%)$ & $77(46 \%)$ & \\
\hline Do not have enough & $21(20 \%)$ & $24(14 \%)$ & \\
\hline \multicolumn{4}{|l|}{ Clinical Characteristics } \\
\hline Months with Heart Failure & $\begin{array}{c}76.97 \pm 79.10 \\
(N=98)\end{array}$ & $70.36 \pm 65.72$ & .472 \\
\hline $\begin{array}{l}\text { Heart Failure type } \\
\text { Systolic/Mixed } \\
\text { Diastolic }\end{array}$ & $\begin{array}{l}83(80 \%) \\
21(20 \%) \\
(N=104)\end{array}$ & $\begin{array}{c}137(82 \%) \\
30(18 \%)\end{array}$ & .648 \\
\hline $\begin{array}{l}\text { Heart Failure Etiology } \\
\text { Ischemic } \\
\text { Nonischemic }\end{array}$ & $\begin{array}{l}18(17 \%) \\
87(83 \%)\end{array}$ & $\begin{array}{l}83(50 \%) \\
83(50 \%) \\
(N=166)\end{array}$ & $<.001$ \\
\hline Left Ventricular Ejection Fraction & $36.54 \pm 16.36$ & $34.51 \pm 17.27$ & .336 \\
\hline NYHA & & & .091 \\
\hline Class I or II & $27(26 \%)$ & $37(22 \%)$ & \\
\hline Class III & $53(51 \%)$ & $105(63 \%)$ & \\
\hline
\end{tabular}




\section{Class IV}

Total Number of Medications

Number of Medications Known to Cause

Daytime Sleepiness

Diuretic

Beta-Blocker

Comorbidity with the Charlson Comorbidity Index Score

Depression measured with the Patient Health Questionnaire (PHQ-9)
$25(24 \%)$

$8.90 \pm 4.02$

$1.50 \pm .98$

$81(77 \%)$

$98(93 \%)$

$2.27 \pm 1.32$

$5.12 \pm 4.03$
$25(15 \%)$

$10.49 \pm 3.80$

.001

$1.60 \pm .98$

.371

.214

.606

$153(92 \%)$

$<.001$

$3.05 \pm 1.72$

$3.88 \pm 3.31$

.009

Note. Comparison of groups via independent sample t-tests or Chi-square test of independence; NYHA = New York Heart Association. 
Table 3

Summary for Sleep Characteristics

\begin{tabular}{|c|c|c|c|c|c|c|}
\hline \multirow[b]{2}{*}{ Characteristics } & \multicolumn{3}{|c|}{ Adults $(\mathrm{N}=105)$} & \multicolumn{3}{|c|}{ Elders $(\mathrm{N}=167)$} \\
\hline & $\begin{array}{l}\text { Mean (SD) } \\
\text { or } N(\%)\end{array}$ & Range & $P$ value & $\begin{array}{l}\text { Mean (SD) } \\
\text { or } N(\%)\end{array}$ & Range & $P$ value \\
\hline \multicolumn{7}{|l|}{ Pittsburgh Sleep Quality Index (PSQI) } \\
\hline Global PSQI Total Score $(0-21)$ & $7.75 \pm 4.16$ & $1-17$ & .084 & $6.86 \pm 3.96$ & $0-19$ & .001 \\
\hline Good Sleeper (Global PSQI > 5) & $21(20 \%)$ & & .833 & $53(32 \%)$ & & .012 \\
\hline Poor Sleeper (Global PSQI $\leq 5)$ & $84(80 \%)$ & & & $114(68 \%)$ & & \\
\hline \multicolumn{7}{|l|}{$\begin{array}{l}\text { PSQI Subscales } \\
(0=\text { Worse, } 3=\text { Better })\end{array}$} \\
\hline Sleep Latency $(0-3)$ & $1.21 \pm 1.08$ & $0-3$ & .551 & $1.09 \pm 0.86$ & $0-3$ & .001 \\
\hline Sleep Duration $(0-3)$ & $1.24 \pm 0.96$ & $0-3$ & .208 & $1.19 \pm 0.99$ & $0-3$ & .031 \\
\hline Habitual Sleep Efficiency $(0-3)$ & $1.05 \pm 1.17$ & $0-3$ & .131 & $0.94 \pm 1.15$ & $0-3$ & .006 \\
\hline Subjective Sleep Quality $(0-3)$ & $1.29 \pm 0.74$ & $0-3$ & .197 & $1.09 \pm 0.86$ & $0-3$ & .040 \\
\hline Sleep Disturbance $(0-3)$ & $1.36 \pm 0.64$ & $0-3$ & .757 & $1.20 \pm .61$ & $0-3$ & .453 \\
\hline Daytime Dysfunction $(0-3)$ & $1.08 \pm 0.85$ & $0-3$ & .110 & $0.71 \pm 0.68$ & $0-3$ & .248 \\
\hline Use of Sleeping Medication $(0-3)$ & $0.53 \pm 1.06$ & $0-3$ & .249 & $0.69 \pm 1.21$ & $0-3$ & .517 \\
\hline \multicolumn{7}{|l|}{ Epworth Sleeping Scale (ESS) } \\
\hline ESS Total Score $(0-24)$ & $7.76 \pm 4.91$ & $0-23$ & $<.001$ & $6.47 \pm 4.33$ & $0-21$ & .178 \\
\hline Sleepy $($ ESS > 10) & $30(29 \%)$ & & $<.001$ & $36(22 \%)$ & & .134 \\
\hline Not Sleepy $(\mathrm{ESS} \leq 10)$ & $75(71 \%)$ & & & $131(78 \%)$ & & \\
\hline Total Sleep Time (hours) & $6.26 \pm 1.65$ & $1-11$ & .305 & $6.34 \pm 1.75$ & $1-10$ & .291 \\
\hline Sleep Disordered Breathing & $55(53 \%)$ & & .471 & $94(56 \%)$ & & .076 \\
\hline Apnea Hypopnea Index per hour & $N=26$ & & .488 & $N=38$ & & .999 \\
\hline$<5$ (No apnea) & $16(62 \%)$ & & & $14(37 \%)$ & & \\
\hline$\geq 5 \&<15$ (Mild) & $5(19 \%)$ & & & $10(26 \%)$ & & \\
\hline$\geq 15 \& \leq 30$ (Moderate) & $4(15 \%)$ & & & $9(23 \%)$ & & \\
\hline$>30$ (Severe) & $1(4 \%)$ & & & $5(13 \%)$ & & \\
\hline
\end{tabular}

Note. Independent sample t-tests or Chi-square test of independence were used to compare sleep characteristics of participants with and without cognitive impairment. 


\section{Table 4}

\section{Summary for Cognitive Tests}

\begin{tabular}{|c|c|c|c|c|c|c|}
\hline \multirow[b]{2}{*}{$\begin{array}{l}\text { Neuropsychologic } \\
\text { Test }\end{array}$} & \multirow[b]{2}{*}{ Unit } & \multirow[b]{2}{*}{$\begin{array}{l}\text { Normal } \\
\text { Range }\end{array}$} & \multicolumn{2}{|c|}{ Adults $(N=105)$} & \multicolumn{2}{|c|}{ Elders $(N=167)$} \\
\hline & & & Mean (SD) & $\begin{array}{l}\mathrm{N}(\%) \text { of } \\
\text { Impaired } \\
\text { Cognition }\end{array}$ & Mean (SD) & $\begin{array}{l}\mathrm{N}(\%) \text { of } \\
\text { Impaired } \\
\text { Cognition }\end{array}$ \\
\hline $\begin{array}{l}\text { Psychomotor } \\
\text { Vigilance Task } \\
\text { (Basner \& Dinges, } \\
\text { 2011; Dinges et } \\
\text { al., 1997) }\end{array}$ & $\begin{array}{l}\text { Transformed } \\
\text { Lapses }\end{array}$ & $<4.69$ & $4.55 \pm 3.59$ & $32(31 \%)$ & $5.31 \pm 3.41 \dagger$ & $75(45 \%) \dagger$ \\
\hline $\begin{array}{l}\text { Trail-Making } \\
\text { Test B (Reitan, } \\
\text { 1992) }\end{array}$ & $\begin{array}{l}\text { Time to } \\
\text { complete, } \\
\text { seconds }\end{array}$ & $\begin{array}{l}\text { Age- } \\
\text { specific } \\
\text { norms }\end{array}$ & $87.19 \pm 48.15$ & $68(65 \%)$ & $125.85 \pm 63.73$ & $102(61 \%)$ \\
\hline $\begin{array}{l}\text { Digit Symbol- } \\
\text { Substitution Test } \\
\text { (The } \\
\text { Psychological } \\
\text { Corporation, } \\
\text { 2002) }\end{array}$ & $\begin{array}{l}\text { Number } \\
\text { correctly } \\
\text { completed } \\
\text { in } 120 \\
\text { seconds }\end{array}$ & $\begin{array}{l}\text { Age- } \\
\text { specific } \\
\text { norms }\end{array}$ & $61.09 \pm 17.47$ & $26(25 \%)$ & $48.53 \pm 15.20$ & $31(19 \%)$ \\
\hline $\begin{array}{l}\text { Probed-Memory } \\
\text { Recall Task } \\
\text { (Dinges et al., } \\
\text { 1993) }\end{array}$ & $\begin{array}{l}\text { Number of } \\
\text { Words } \\
\text { recalled }\end{array}$ & $\begin{array}{l}>1 \text { of } 4 \\
\text { words }\end{array}$ & $2.49 \pm 1.27$ & $23(22 \%)$ & $1.75 \pm 1.13$ & $68(41 \%)$ \\
\hline $\begin{array}{l}\text { Letter Number } \\
\text { Sequencing } \\
\text { Subtest (The } \\
\text { Psychological } \\
\text { Corporation, } \\
\text { 2002) }\end{array}$ & $\begin{array}{l}\text { Number of } \\
\text { correctly } \\
\text { recalled } \\
\text { sequences }\end{array}$ & $\begin{array}{l}\text { Age- } \\
\text { specific } \\
\text { norms }\end{array}$ & $9.78 \pm 3.26$ & $11(11 \%)$ & $8.07 \pm 3.48$ & $33(20 \%)$ \\
\hline $\begin{array}{l}\text { Cognitive } \\
\text { Impairment }\end{array}$ & & & & $33(31 \%)$ & & $74(44 \%)$ \\
\hline
\end{tabular}


Table 5

Spearman correlation matrix of nighttime sleep quality and excessive daytime sleepiness with each cognitive test

\begin{tabular}{|c|c|c|c|c|}
\hline & \multicolumn{2}{|c|}{ Adults $(N=105)$} & \multicolumn{2}{|c|}{ Elders $(N=167)$} \\
\hline $\begin{array}{l}\text { Pittsburgh Sleep } \\
\text { Quality Index } \\
\text { (PSQI) }\end{array}$ & PSQI & ESS & PSQI & ESS \\
\hline $\begin{array}{l}\text { Epworth Sleeping } \\
\text { Scale (ESS) }\end{array}$ & $.384 * *$ & & $.160^{*}$ & \\
\hline $\begin{array}{l}\text { Psychomotor } \\
\text { Vigilance Task }\end{array}$ & $.397 * *$ & $.284 * *$ & $.179 * \dagger$ & $.130 \dagger$ \\
\hline Trail-Making Test B & .048 & $.198 *$ & $.224 * *$ & -.017 \\
\hline $\begin{array}{l}\text { Digit Symbol- } \\
\text { Substitution Test }\end{array}$ & -.095 & -.087 & $-.244 * *$ & .020 \\
\hline $\begin{array}{l}\text { Probed-Memory } \\
\text { Recall Task }\end{array}$ & .007 & $-.266^{* *}$ & $-.212^{* *}$ & .141 \\
\hline $\begin{array}{l}\text { Letter Number } \\
\text { Sequencing Subtest }\end{array}$ & -.190 & $-.232 * *$ & $-.227 * *$ & .072 \\
\hline
\end{tabular}

Note. $* p<.05, * * p<.01 . \dagger \mathrm{N}=163$ 
Table 6

Multivariate Logistic Regression Model for Cognitive Impairment

\begin{tabular}{|c|c|c|c|c|c|c|}
\hline \multirow[b]{2}{*}{ Characteristics } & \multicolumn{3}{|c|}{ Adults $(N=105)$} & \multicolumn{3}{|c|}{ Elders $(N=166)$} \\
\hline & Odds ratio & $95 \% \mathrm{CI}$ & $p$ value & Odds ratio & $95 \% \mathrm{CI}$ & $p$ value \\
\hline Global PSQI & .97 & $.81-1.18$ & .791 & 1.16 & $1.03-1.31$ & .017 \\
\hline Epworth Sleeping Scale & 1.25 & $1.08-1.45$ & .003 & .92 & $0.83-1.02$ & .094 \\
\hline Age & 1.04 & $.97-1.12$ & .283 & 1.08 & $1.01-1.14$ & .015 \\
\hline \multicolumn{7}{|l|}{ Gender } \\
\hline Female & Reference & & & & & \\
\hline Male & 2.10 & $.59-7.43$ & .252 & 0.75 & $0.28-2.00$ & .569 \\
\hline \multicolumn{7}{|l|}{ Race } \\
\hline White & Reference & & & & & \\
\hline Black/Others & 1.28 & $.35-4.67$ & .708 & 1.19 & $0.47-2.99$ & .713 \\
\hline Education in Years & 1.28 & $.96-1.71$ & .089 & .95 & $0.80-1.11$ & .497 \\
\hline ANART & .89 & $.83-.96$ & .001 & .97 & $.93-1.01$ & .172 \\
\hline \multicolumn{7}{|l|}{ NYHA } \\
\hline Class IV & Reference & & & & & \\
\hline Class I or II & 1.54 & $.27-8.86$ & .629 & .52 & $0.13-2.05$ & .352 \\
\hline Class III & .38 & $.09-1.56$ & .178 & .33 & $0.10-1.05$ & .061 \\
\hline $\begin{array}{l}\text { Charlson Comorbidity } \\
\text { Index Score }\end{array}$ & 1.05 & $0.64-1.72$ & .839 & 1.12 & $0.87-1.45$ & .366 \\
\hline $\begin{array}{l}\text { Patient Health } \\
\text { Questionnaire }\end{array}$ & 1.07 & $0.90-1.28$ & .437 & .960 & $0.83-1.11$ & .572 \\
\hline
\end{tabular}

Note . CI = Confidence Interval; PSQI = Pittsburgh Sleep Quality Index; ANART = American National Adult Reading Test; NYHA = New York Heart Association; The model was also adjusted for recruitment site; There was a statistical difference in cognitive impairment between sites in elders. 